\title{
Shiitake dermatitis in a 5-year old boy: First pediatric case report
}

\author{
Philip Johnson*1, Aimee Arits $^{2}$, Yvan Vandenplas ${ }^{1}$ \\ ${ }^{1}$ Department of Pediatrics, Universitair Ziekenhuis Brussel, Vrije Universiteit Brussel (VUB), Brussels, Belgium \\ ${ }^{2}$ Department of Dermatology, Maastricht University Medical Centre, Maastricht, the Netherlands
}

Received: April 8, 2016

DOI: $10.5430 /$ crim.v3n3p1
Accepted: May 3, 2016

URL: http://dx.doi.org/10.5430/crim.v3n3p1

\begin{abstract}
Shiitake mushrooms are increasingly being consumed in the West because of their possible health benefits and changing dietary preferences. A rare but increasingly occurring undesired effect caused by the thermolabile polysaccharide lentinan in the Shiitake mushroom is the incidence of a particular toxic dermatitis called flagellate dermatitis or Shiitake dermatitis. This dermatitis is extremely pruritous, heals without scarring in one to eight weeks and the effect of treatment is doubtful. The pathogenesis has not been completely explained and it is unclear why some people react more than others. We here present what we believe to be the first pediatric case of Shiitake dermatitis in a 5-year-old boy.
\end{abstract}

Key Words: Shiitake, Flagellate dermatitis, Toxicodermia

\section{INTRODUCTION}

With globalization and a growing interest in foreign cuisine, new ingredients are increasingly being introduced into our homes. Consumption of Shiitake mushrooms, a food product originating from Japan and China, is becoming widespread in the West. Recent research is showing evidence of beneficial effects such as immune modulation ${ }^{[1]}$ and lowering of the blood cholesterol. ${ }^{[2]}$ However, consumption of Shiitake mushrooms can also cause undesirable effects. "Shiitake dermatitis", also known as flagellate dermatitis or toxicoderma is caused by the ingestion of raw or partially cooked Shiitake mushrooms. It can also occur in those who cultivate these mushrooms themselves. We present to our knowledge the first published pediatric case of flagellate dermatitis following consumption of Shiitake mushrooms.

\section{Case presentation}

A 5-year-old boy presented at the emergency room because of a non-pruritic rash mainly on the trunk and proximal limbs since earlier that morning. There was no fever and there were no other associated symptoms. There was no relevant medical history and he had not been ill recently. There were no other family members with the same symptoms. He had had no contact with animals. The day before presentation, the patient had been playing in the forest.

Physical examination showed an otherwise healthy child with a papulo-vesicular rash on the abdomen and upper legs and an urticarial linear rash on the abdomen and lower back (see Figures 1, 2). Dermographism was negative. Upon suspicion of an infectious rash or toxic reaction to plants, antihistaminic medication was prescribed and the patient returned home.

The next day, the rash had worsened and had become intensely pruritic. The mother of the child had developed the same pruritic rash. A further dietary history taking revealed that the day before presentation of the rash, the family had prepared shiitake mushrooms in the wok. The patient and

\footnotetext{
*Correspondence: Philip Johnson, MD; Email: Philip.johnson.md@gmail.com; Address: Department of Pediatrics, UZ Brussel Laarbeeklaan 101, Brusse 11090, Belgium. 
his mother were the only affected family members. Symptomatic antihistaminic therapy was continued and the rash completely resolved after 1-2 weeks.

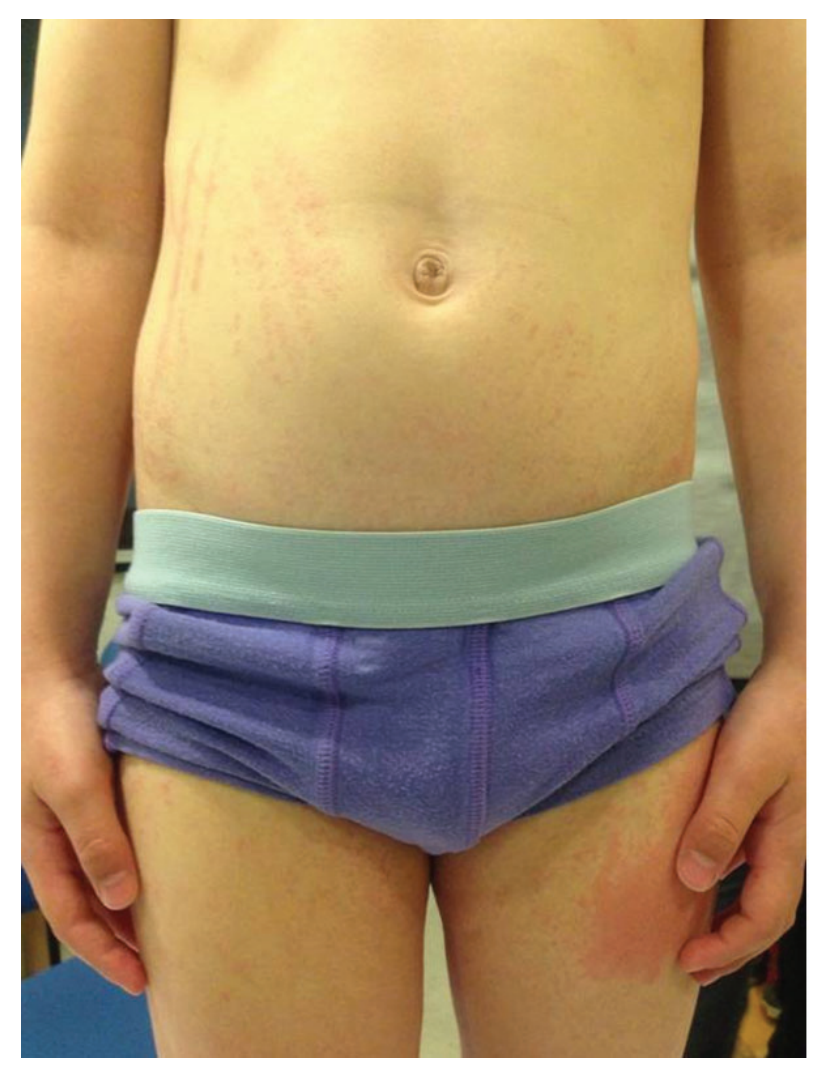

Figure 1. Truncal and limb involvement of toxicoderma

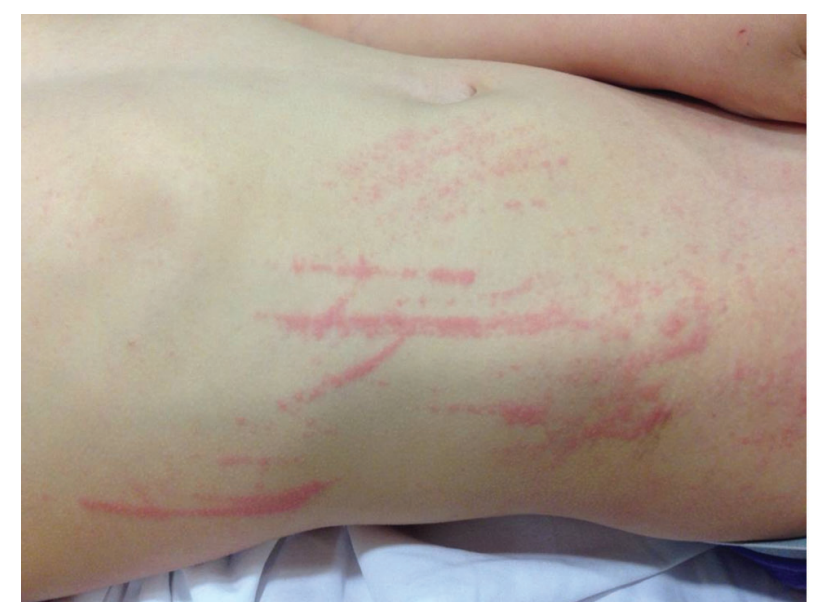

Figure 2. Typical flagellate pattern of lesions in Shiitake dermatitis caused by scratching

\section{DisCUSSION}

Shiitake mushrooms are increasingly being consumed in the West due to their potential health benefits. An infrequent but important side effect of the ingestion of the mushroom, is the development of a typical strongly pruritic toxic dermatitis called Shiitake dermatitis or toxicoderma. ${ }^{[3]}$ It is also known as Flagellate dermatitis, a name derived from the medieval Christian "flagellant" movement, in which the members would whip themselves as a penance for sins (from the Latin flagellum: whip) ${ }^{[4]}$ The clinical picture is very characteristic: apart from widespread erythematous small papules, sometimes edema and vesicles occur. Scratching leads to long, flagellate streaks composed of petechiae or papules on the trunk and extremities. The dermatitis is extremely itchy. ${ }^{[3-9]}$ The disease is self-limiting and it is doubtful if therapy with antihistaminic medication or topical corticosteroids reduces the duration or the severity of the symptoms. ${ }^{[5]}$ Diagnosis is based on clinical presentation and dietary history of the last few days. Provocation tests are rarely useful and neither skin biopsy nor blood tests are specific. ${ }^{[3-8]}$

Although the first case was described by Nakamura in Japan in $1977,{ }^{[7]}$ it is still relatively uncommon in the West. The first case report in Europe was published in $1991^{[6]}$ and the next one only in 2006. ${ }^{[8]}$ It is increasingly being seen and recognized by dermatologists but many general practitioners and particularly pediatricians will not have enough exposure to this clinical picture to diagnose it correctly. Correct diagnosis is important to prevent recurrence as sensitive individuals will likely repeatedly develop the rash after subsequent ingestion of the mushrooms. ${ }^{[9]}$

The skin reaction is believed to be caused by lentinan, a thermolabile polysaccharide found in the Shiitake mushroom. It denaturizes at a temperature of $130-145{ }^{\circ} \mathrm{C}$, making it essential to cook the mushrooms well before ingesting them. ${ }^{[3,10]}$ More recently, an interesting new theory has risen. Tan argues that the growth method of the mushroom may also contribute to the occurrence of the rash. In China, the shiitake mushrooms are "substrate grown": the spores are seeded onto sawdust or straw. Very few cases of toxicoderma have been reported here. Previously in Japan, the mushrooms used to be "log grown", with the spores being directly seeded onto tree logs. Significantly more cases were reported. Around 1992-1993, when Japan started importing substrate grown mushrooms from China, the reported incidence of the dermatitis dropped markedly. ${ }^{[11]}$

It is known that lentinan triggers secretion of Interleukin-1 which leads to vasodilatation. However, the complete pathway has not yet been discovered and it is not known why certain individuals are more susceptible than others. ${ }^{[4,12]} \mathrm{We}$ have not found any evidence in the literature for any specific genetic predisposition. However, in an article on drug eruptions in general, it is argued that specific Human Leukocyte 
Antigen (HLA) alleles are known to be associated with various severe reactions to some drugs. ${ }^{[13]}$ This could explain why both the patient and his mother were affected and not the father. Unfortunately, we did not obtain our patients HLA type nor his mothers.

Of particular interest is the fact that a common side effect of bleomycin, a chemotherapeutic agent, is the occurrence of a very similar flagellate dermatitis, except in this case a hyperpigmentation of the skin is also frequently observed. In the case of bleomycin, the lesions do not always disappear completely whereas the dermatitis caused by lentinan virtually always heals without scarring within one to eight weeks when the mushrooms are avoided. ${ }^{[4,8]}$

\section{Conclusion}

Shiitake dermatitis is a rare undesired effect of the ingestion of particularly raw or partially cooked Shiitake mushrooms, Though intensely pruritic, the dermatitis is harmless and will disappear within one to eight weeks. It is thought to be caused by the thermolabile polysaccharide lentinan, making correct preparation of the mushroom essential. Diagnosis is based solely on dietary history and clinical examination as the pattern of the skin lesions is particularly unique.

With this 5-year-old boy we present what is to our knowledge the first pediatric case report of Shiitake dermatitis in medical literature.

\section{REFERENCES}

[1] Dai X, Stanilka J, Rowe C, et al. Consuming Lentinula edodes (Shiitake) Mushrooms Daily Improves Human Immunity: A Randomized Dietary Intervention in Healthy Young Adults. J Am Coll Nutr. 2015; 34: 478-8. PMid:25866155 http://dx.doi.org/10.1080/073 15724.2014 .950391

[2] Yang H, Hwang I, Kim S, et al. Lentinus edodes promotes fat removal in hypercholesterolemic mice. Exp Ther Med. 2013; 6: 1409-1413. PMid:24255670

[3] Nakamura T. Shiitake (Lentinus edodes) dermatitis. Contact dermatitis. 1992; 27: 65-70. PMid:1395630 http://dx.doi.org/10.11 11/j.1600-0536.1992.tb05211.x

[4] Hiernickel C, Metz S, Elsner P. Shiitake dermatitis: an impressive case report. J Dtsch Dermatol Ges. 2015; 13: 455-6. http: //dx.doi.org/10.1111/ddg. 12597

[5] Boels D, Landreau A, Bruneau C, et al. Shiitake dermatitis recorded by French Poison Control Centers - new case series with clinical observations. Clin Toxicol (Phila). 2014; 52: 625-8. PMid:24940644 http://dx.doi.org/10.3109/15563650.2014.923905

[6] Tarvainen K, Salonen J, Kanerva L, et al. Allergy and toxicodermia from shiitake mushrooms. J Am Acad Dermatol. 1991; 24: 64-6.
http://dx.doi.org/10.1016/0190-9622(91)70011-P

[7] Nakamura T. Toxicoderma caused by shiitake (lentinus edodes). Jpn J Clin Dermatol. 1977; 31: 65-8.

[8] Mak R, Wakelin S. Shiitake dermatitis: the first case report from a European country. Br J Dermatol. 2006; 154: 800-1. PMid:16536844 http://dx.doi.org/10.1111/j.1365-2133.2006.07174.x

[9] Garg S, Cockayne S. Shiitake dermatitis diagnosed after 16 years! Arch Dermatol. 2008; 144: 1241-2. PMid:18794485 http://dx.d oi.org/10.1001/archderm.144.9.1241

[10] Wang X, Xu X, Zhang L. Thermally induced conformation transition of triple-helical lentinan in $\mathrm{NaCl}$ aqueous solution. J Phys Chem B 2008; 112: 10343-51. PMid:18661940 http://dx.doi.org/10 1021/jp802174v

[11] Tan Q, Tan C. Log-grown shiitake is perhaps the real cause for Shiitake dermatitis. J Eur Acad Dermatol Venereol. 2016; 30: 197-8. PMid:25208952 http://dx.doi.org/10.1111/jdv. 12712

[12] Hanada K, Hashimoto I. Flagellate mushroom (Shiitake) dermatitis and photosensitivity. Dermatology. 1998; 197: 255-7. PMid:9812031 http://dx.doi.org/10.1159/000018007

[13] de la Torre C, Suh Oh H. Advances in the diagnosis of drug eruptions. Actas demosifiliogr. 2013; 104: 782-788. 